\title{
Article
}

\section{The effects of motivational climate interventions on psychobiosocial states in high school physical education}

Bortoli, Laura, Bertollo, Maurizio, Vitali, Francesca, Filho, Edson and Robazza, Claudio

Available at http://clok.uclan.ac.uk/14154/

Bortoli, Laura, Bertollo, Maurizio, Vitali, Francesca, Filho, Edson ORCID: 00000002-8548-4651 and Robazza, Claudio (2015) The effects of motivational climate interventions on psychobiosocial states in high school physical education. Research Quarterly for Exercise and Sport, 86 (2). pp. 196-204. ISSN 0270-1367

It is advisable to refer to the publisher's version if you intend to cite from the work. http://dx.doi.org/10.1080/02701367.2014.999189

For more information about UCLan's research in this area go to

http://www.uclan.ac.uk/researchgroups/ and search for < name of research Group>.

For information about Research generally at UCLan please go to http://www.uclan.ac.uk/research/

All outputs in CLoK are protected by Intellectual Property Rights law, including Copyright law. Copyright, IPR and Moral Rights for the works on this site are retained by the individual authors and/or other copyright owners. Terms and conditions for use of this material are defined in the policies page. 
The Effects of Motivational Climate Interventions on Psychobiosocial States in High School Physical Education

\author{
Laura Bortoli and Maurizio Bertollo \\ University of Chieti-Pescara \\ Francesca Vitali \\ University of Verona \\ Edson Filho and Claudio Robazza \\ University of Chieti-Pescara
}

Correspondence should be addressed to Claudio Robazza, Department of Medicine and Aging Sciences, University “G. D’Annunzio”, via dei Vestini, 31 - 66013 Chieti, Italy, Tel. +39(0)871-3554052, fax +39-(0)871-3556754, e-mail c.robazza@unich.it 
Author's Note

This research was funded by a grant from the Italian Ministry of Instruction, University, and Research for Scientific Research Programs of Relevant National Interest (PRIN; programmi di ricerca scientifica di rilevante interesse nazionale). 
Abstract

Purpose: The purpose of this study was to examine the effects of task- and ego-involving climate manipulations on students' climate perception and psychobiosocial (PBS) states in a physical education setting. Method: Two subsamples of female students $(N=108,14-15$ years of age) participated for 12 lessons on either a task- or an ego-involving climate intervention as grounded in the TARGET model. Results: At the end of the treatment, the participants of the ego-involved group reported lower scores in perceived task-involving climate and higher scores in perceived ego-involving climate than their peers in the taskinvolved group. Lower scores in pleasant/functional PBS states and higher scores in unpleasant/dysfunctional PBS states were also observed in the ego-involved group as a consequence of the intervention. Conclusion(s): Findings suggested that teacher's induced achievement motivational climates can influence students' perceptions and prompt PBS states consistent with the motivational atmosphere.

Keywords: motivation, achievement goal theory, emotions 
The Effects of Motivational Climate Interventions on Psychobiosocial States in High School Physical Education

A critical reduction of physical activity and sport participation during adolescence is well documented (Bassoli et al., 2004; Biddle, Whitehead, O’Donovan, \& Nevi, 2005). Thus, one of the main objectives of physical education (PE) is to encourage adolescents' participation in regular physical activity by providing students with pleasant and rewarding experiences in the school context. Indeed, pleasant emotional states, such as enjoyment, have been linked to adolescents' sport and exercise involvement (Biddle et al., 2005). Scanlan and Simons (1992) described enjoyment as a positive affective state that reflects feelings such as pleasure, liking, and fun. Enjoyable PE programs are expected to encourage adolescents to become more active, particularly girls who tend to be less physically active than boys (see Wallhead \& Buckworth, 2004, for a review).

In the study of performance-related emotions of athletes, Hanin (2000) developed the individual zones of optimal functioning (IZOF) model, in which pleasant/functional and unpleasant/dysfunctional psychobiosocial (PBS) states are considered. PBS states are defined as situational, multimodal, and dynamic manifestations of the total human functioning, whereby emotion is viewed in a multidimensional manner and as a fundamental component of an individual's experience (Hanin, 2007). PBS states consist of at least seven pleasant or unpleasant, functional or dysfunctional interactive components included in psychological (cognitive, emotional, motivational), biological (bodily, kinesthetic), and social (performance, communicative) categories. Accordingly, the individual's emotional experience is understood and described through a holistic and detailed perspective. As conceptualized within the IZOF model, PBS states have been recently studied in PE (Bortoli, Bertollo, Filho, \& Robazza, 2014; Bortoli \& Robazza, 2007) and youth sport (Bortoli, Messina, Zorba, \& Robazza, 2012). However, previous research on this topic has been correlational in nature where causality 
inferences cannot be implied. As such, we conducted a quasi-experimental study in an attempt to advance the knowledge on the linkage between motivational climate and PBS states in high school girls.

Appropriate educational and psychological approaches in high school PE can play a crucial role in promoting physical activity engagement in and out of school. A motivational perspective widely applied in the school context is the achievement goal theory (Ames, 1992). This theory purports that two major achievement goals, namely "task" orientation and "ego" orientation, operate in achievement settings and reflect different meanings assigned to perceived success and failure. In task orientation, perception of ability is self-referenced and success is considered on the basis of personal improvement, progression in learning, and performing one's best. In ego orientation, perception of ability is normatively referenced and success is a function of social comparison in the attempt of outperforming others. Compared to ego-oriented peers, high task-oriented students were shown to be more intrinsically motivated, enjoy learning experiences more frequently, feel less boredom, and experience positive activating emotions, such as enjoyment, hope, and pride (Mouratidis, Vansteenkiste, Lens, \& Vanden Auweele, 2009).

The social context created by significant others can influence the likelihood of whether a person will be task- or ego-involved when participating in an activity (see Roberts, Treasure, \& Conroy, 2007). Teachers might endorse a motivational climate that underscores social comparison and competition (i.e., performance or ego-involving climate) or promotes learning and cooperation (i.e., mastery or task-involving climate). Research in PE has shown that individual's perception of a task-involving climate is related to intrinsic motivation, pleasant emotional states, enjoyment, positive attitudes toward the lesson, high perceived ability, interest in PE, satisfaction, and adaptive cognitive processes (see Biddle, 2001, for a review; Bortoli \& Robazza, 2007). 
Physical education teachers can thus play an important role in enhancing students' motivation and should adopt practices to improve a task-involving motivational climate. A useful basis to promote task-involving climates in classroom settings is the TARGET model developed by Epstein (see Ames, 1992). TARGET is the acronym of the six different dimensions that constitute the program: Tasks, Authority, Recognition, Grouping, Evaluation, and Time. In a high task-involving motivational climate students work on different tasks at their own ability level, are permitted to choose the tasks in which they will participate (i.e., can make choices concerning activities), have opportunities to receive rewards, work in mixed-ability groups, are evaluated on their own objectives, and have flexible time for task completion. As described in detail elsewhere (see Biddle, 2001; Treasure, 2001), the TARGET approach is aimed at providing students with successful learning experiences through the monitoring of individual progress and the establishment of challenging and diverse goals. For instance, "Authority" is shared and the students set the rules for each class together with the teacher. Furthermore, "Evaluation" and "Recognition" are given on an individual basis as students are rewarded for their personal development and achievements.

Research in PE has shown that manipulation of TARGET dimensions can influence goal orientation as well as cognitive, behavioral, and affective variables. In a recent metaanalysis, Braithwaite, Spray, and Warburton (2011) synthesized findings from 22 papers describing interventions in which the TARGET model was applied in the PE setting. Collectively, results were consistent with achievement goal theory literature showing adaptive outcomes for groups experiencing a task-involving climate, and negative outcomes for egoinvolving climate experiences. Yet, the TARGET model was fully applied with high school aged students (14-15 years old) in three of these studies only. Students showed enhanced intrinsic motivation (Jaakkola \& Liukkonen, 2006), improved perception of competence, greater satisfaction, and less boredom toward PE classes (Weigand \& Burton, 2002). Only in 
the latter study emotional aspects were considered. There is, thus, a need for additional research on this topic in high school PE through experimental and quasi-experimental research protocols, particularly among female students. As research has documented, engagement in physical activity outside of school decreases with age, mainly during adolescence, with girls being less active than boys at all ages (see Biddle et al., 2005, for a review).

\section{Aims of the Present Study}

In the present investigation, we addressed emotional issues associated with PE interventions. The first purpose was to examine the effect of manipulating the motivational climate on students' climate perception, while taking into account the effect of individual goal orientation. In the achievement goal theory, perceptions of motivational climate and dispositional goal orientations are two independent dimensions of motivation that interact to influence behavior. When the situational criteria are weak, an individual dispositional goal orientation tends to prevail. In contrast, when the situational criteria are particularly salient, perceptions of the climate tend to override an individual's dispositional goal orientation and be a stronger predictor of outcomes (see Roberts et al., 2007). Thus, we expected that a specific task- or ego-involving climate triggered by the PE teacher would determine a students' climate perception consistent with the climate induced.

The second purpose was to examine the effect of a task- or ego-involving climate on adolescent students' PBS states. Previous studies on achievement goal theory in PE showed that task-involving climate interventions resulted in more adaptive affective, behavioral, and cognitive outcomes, whereas ego-involving climate led to more negative consequences (Braithwaite et al., 2011). According to a previous study in PE on motivation and PBS states (Bortoli \& Robazza, 2007), we expected to find task-involving climate positively related to 
pleasant/functional PBS states, and ego-involving climate associated with unpleasant/dysfunctional PBS states.

\section{Method}

\section{Participants}

The study initially included 112 female students $\left(M_{\text {age }}=14.40\right.$ years, age range: $14-15$ years) drawn from two high schools in northeastern Italy. Students participated in PE as a required course twice a week, for 50 min each lesson, during their first year of high school. The headmasters gave permission to conduct the study after the researchers explained to them the general purposes of the intervention. The intervention included four experimental groups (two groups for each school), two of them involved in a task-involving climate and the other two in an ego-involving climate. Noteworthy, PE teachers are not neutral actors, falling somewhere within the task- and ego-climate continuum (Braithwaite et al., 2011). Therefore, the ecological nature of our investigation did not allow for the establishment of a clear control group. Specifically, we opted for contrasting two clearly defined experimental groups while checking for equality of initial states (see Table 1) to ensure that the groups did not differ at pretest. Four girls were excluded from data analysis because they missed one or more lessons due to health issues, and therefore were not able to undertake the complete PE program. The final sample $(N=108)$ was thus composed of 51 students in the two task-involved groups $(25$ and 26 girls) and 57 students in the two ego-involved groups (28 and 29 girls).

\section{Measures}

Perceived Motivational Climate. Student's perceptions of the motivational climate were assessed to determine whether the intervention was effective in creating a particular psychological climate. We used the Teacher-Initiated Motivational Climate in Physical Education Questionnaire (TIMCPEQ; Papaioannou, 1998), which consists of two 6-item scales. The teacher-initiated mastery orientation scale measures the teacher's emphasis on 
skill mastery and effort (e.g., "The physical education teacher is most satisfied when every student learns something new"). The teacher-initiated performance orientation scale gauges the teacher's emphasis on social comparison and competition (e.g., "Only the students with the best records are rewarded"). Following the stem "In this physical education class", students indicate their responses on a 5-point scale ranging from 1 "strongly disagree" to 5 "strongly agree". The Italian version of the TIMCPEQ was administered to boys and girls aged 11 to 14 years (Bortoli, Colella, Morano, Berchicci, Bertollo, \& Robazza, 2008). Confirmatory factor analysis provided support for the two-dimensional structure of the questionnaire $\left(\chi^{2}=254.67, d f=53, p<.001, \chi^{2} / d f=4.81, \mathrm{GFI}=.95, \mathrm{NNFI}=.91, \mathrm{CFI}=.92\right.$, and RMSEA = .07). In this study, Cronbach $\alpha$ values for both the mastery and performance scale scores were .71 .

Goal Orientation. Individual's goal orientation was also assessed to determine the effectiveness of the intervention, as well as to control for the possible interactions with the perceived motivational climate. Walling and Duda (1995) modified the Task and Ego Orientation in Sport Questionnaire (TEOSQ; Duda \& Nicholls, 1992) for use within the PE context. Eight items measure individuals' disposition for ego orientation (e.g., “...I'm the best”) and eight items assess individual's disposition for task orientation (e.g., “...I do my very best"). With a stem of "I feel really successful in physical education when..." students are asked to respond on a 5-point scale anchored by 1 "strongly disagree" and 5 "strongly agree". Bortoli and Robazza (2005) translated and adapted into Italian the modified version of the TEOSQ and administered it to boys and girls ranging in age from 14 to 19 years. Confirmatory factor analysis supported the two-factor solution (girls $14-16$ years, $\chi^{2}=$ 409.63, $d f=103, p<.001, \chi^{2} / d f=3.98, \mathrm{GFI}=.90, \mathrm{NNFI}=.90, \mathrm{CFI}=.91$, and $\mathrm{RMSEA}=$ .08). In the current study, internal consistency yielded Cronbach $\alpha$ values of .91 for the ego factor scores and .84 for the task factor scores. 
Psychobiosocial States. We assessed PBS states in the PE domain through a 14-item list of pleasant/functional descriptors (seven items) and unpleasant/dysfunctional descriptors (seven items). Bortoli and Robazza (2007) identified the descriptors based on existing lists of adjectives used to assess emotional experiences in youth sport and PE (e.g., Robazza \& Bortoli, 2005). Adjectives pertained to each of the seven PBS components conceptualized within the IZOF model (Hanin, 2000). An item (discrete PBS state) comprises two or three descriptors, rather than just one descriptor, in order to transmit a clear and direct representation of an emotional experience related to the PE context. Pleasant/functional or unpleasant/dysfunctional items for each PBS component are: "happy, joyful, cheerful”, and “depressed, sad" (emotion); “convinced, resolute, purposeful”, and “inactive, sluggish, passive" (cognition); "involved, determined, committed", and "unmotivated, disengaged" (motivation); "physically fresh, reactive", and "tense, stiff muscles" (bodily reaction); "active, dynamic", and "awkward, clumsy" (movement); "capable, proficient, effective", and “doubtful, unsure, uncertain" (performance); "socializing, collaborative”, and "lonely, isolated" (communication). Students are asked to rate each item on a five-point scale ranging from 0 "not at all" to 4 "very, very much", thinking of how they usually feel within their PE context. Bortoli and Robazza (2007) found a two-factor solution (i.e., pleasant/functional and unpleasant/dysfunctional dimensions) to be acceptable $\left(\chi^{2}=272.08, d f=76, p<.001, \chi^{2} / d f=\right.$ $3.58, \mathrm{GFI}=.95, \mathrm{NNFI}=.93, \mathrm{CFI}=.94$, and RMSEA $=.06)$. In this study, Cronbach $\alpha$ values were .83 for the pleasant/functional scale scores and .75 for the unpleasant/dysfunctional scale scores.

\section{Procedure}

Participants and their parents gave assent, and parents signed an informed consent. The ethics committee of the local university approved the study, which included seminars with teachers, two data collection meetings, and the intervention phase. We held three $2 \mathrm{hr}$ 
seminars with teachers prior to data collection and intervention, as well as three meetings during treatment lasting approximately $40 \mathrm{~min}$ each. Our goal was to discuss and share with teachers the basics and the principles underpinning the intervention and to design lesson plans. Each teacher was responsible for a "task-involved group" and an "ego-involved group". Presentations and discussions covered relevant theoretical and practical publications on motivational climate and goal orientation. In particular, the interaction focused on the theoretical and methodological issues stemming from the TARGET-model (Ames, 1992). Emphasis was placed on the principles of task, authority, rewards, grouping, evaluation, and timing. For example, students of the task-involved group were: (a) stimulated to engage in individualized tasks and participate in decision-making during the lessons; (b) praised for improving and exerting effort; (c) involved in mixed-ability groups; (d) evaluated based on self-referenced criteria; and (e) allowed to determine the pace of learning based on their goals and progresses. Teachers were also notified that they could adjust the content of the lessons based on their program, schedule, and school's facilities. However, they had to follow, as much as possible, the recommendations for creating a task-involving climate or an egoinvolving climate.

To ensure implementation of the two experimental conditions, in the three meetings during treatment teachers were asked to present their lesson plans and examine the methods they used. The discussion focused on the tasks they used, the way they designed the drills, the decision-making and evaluation processes, the type of feedback provided, and the problems occurring during the lessons. Furthermore, during intervention a task-involving lesson and an ego-involving lesson were videotaped from each teacher and then discussed. Noteworthy, teachers from the two different conditions were not debriefed together, in an effort to minimize cross-contamination of the experimental conditions. Also noteworthy, the experimental conditions did not involve the manipulation of mastery and performance goals 
avoidance, as outlined in Elliot and McGregor's (2001) $2 \times 2$ framework. Accordingly, our experimental manipulation was specific to the class environment as established by the teachers rather than the goal approach favored by the students.

Pretest and post-test took place two days prior to and after treatment. Assessment occurred in groups of four or five students in a quiet place near to the PE facilities, without the presence of the teacher. One of the authors administered the questionnaires to the participants. The entire set of questionnaires took approximately $20 \mathrm{~min}$ to complete. Participants were informed about their voluntary status, and assured that their individual data would be treated in confidence by the researchers. Students were asked to complete the questionnaires thinking about their current experience in $\mathrm{PE}$ and told that there were no right or wrong answers. The importance of honesty when completing the questionnaires was emphasized. We made sure that participants thoroughly understood the instructions and items, and remained available to clarify possible doubts or misunderstandings.

Given that the general purpose of this study was to investigate task- and ego-involving climate interventions in a real world setting, we adopted a quasi-experimental design without random assignment of participants to groups. Therefore, intact classes were assigned to experimental groups. The intervention consisted of 50 min lessons twice a week for six weeks (12 lessons in total), and started two months after the beginning of the academic year. As previously stated, the two teachers were both responsible for a "task-involved group" and an "ego-involved group", and initiated the experimental activities approximately in the same period.

We prepared lesson plans together with the teachers. Warm-up and cool-down exercises, lasting about 5 to $10 \mathrm{~min}$, opened and closed each lesson. The core part of each lesson lasted about $30 \mathrm{~min}$ and contained at least three activities. The four groups were involved in learning and performing a number of fundamental gymnastics tasks often used in 
PE as part of the academic curriculum. These tasks were deemed appropriate for the purpose of our study on motivational climate in PE classes, because gymnastic skills are frequently taught to boys and girls in Italian middle and high schools. In addition, during our preparatory seminars, both teachers identified gymnastics as a topic of interest for most girls. Gymnastic exercises for novices included floor acrobatics, vaulting, forward and backward walks on the balance beam, and mini-trampoline jumps. Floor acrobatics encompassed forward roll, backward roll, assisted handstand, handstand and forward roll, backward roll and handstand, dive forward roll, and cartwheel. Vaulting comprised side, squat, and straddle vaults. Minitrampoline exercises involved straight, straddle, and tuck jumps. The teacher supervised all activities and provided direct assistance when necessary.

The designed activities incorporated main indicators derived from the TARGETmodel (Ames, 1992) and a number of authors (e.g., Morgan \& Kingston, 2008; Papaioannou \& Goudas, 1999). The task-involved group engaged in a range of tasks gradually varying in the level of difficulty (e.g., from forward roll to backward roll, or from forward to backward walk on the balance beam). Activities were individualized according to an individual's skill level and time needed to learn and improve performance. Students were invited to set specific and short-term goals, evaluate themselves on their goals, and keep track of personal progresses toward the goals based on self-referenced criteria. They were also encouraged to take part in decision-making (e.g., choosing the tasks, assigning time to the task engagement, deciding intensity and frequency of personal involvement in an activity), work in pairs, work in small groups of similar or different ability level and develop social interactions. The teacher showed appreciation, and acknowledged the students' improvement, attainment of individual goals, exertion of effort, and participation in the activities.

The ego-involved group was not permitted to engage in individualized activities based on the personal skill level. Rather, it was the teachers' schedule and goals that determined the 
progression from one task to another. Hence, students did not set goals, evaluate themselves, or participate in decision-making. Activities were organized at an individual level rather than in pairs or groups. Students were publically praised for reaching high-level performance or better achievements in comparison with their classmates. Personal improvements, effort, and participation were not valued.

\section{Data Analysis}

Data of the two task-involved groups and the two ego-involved groups were aggregated for analysis. Data were screened for missing data, potential outliers, and violations of assumptions of normality, linearity, and homoscedasticity (Tabachnick \& Fidell, 2013). Descriptive statistics, scale reliability, and Pearson product-moment correlation coefficients were computed for all measures collected at pretest. Group homogeneity on all measures at pretest was checked using $t$-tests for independent samples.

A $2 \times 2$ (group $\times$ test) repeated-measures analysis of covariance $($ RM-ANCOVA) was performed on the scores of each dependent variable to determine the effect of the intervention. Task orientation and Ego orientation were entered as covariates in the analysis to control for the possible interaction between motivational climate and goal orientation. Post-hoc comparisons with Bonferroni adjustment to control for the Type-I error rate were then conducted to identify the source of any statistically significant effect.

We also conducted a profile analysis on the post-test scores of pleasant/functional and unpleasant/dysfunctional PBS states to identify which of the discrete PBS states were significantly different in the two experimental groups. Profile analysis is an application of multivariate analysis of variance to several dependent variables measured on the same scale (Tabachnick \& Fidell, 2013).

\section{Results}

\section{Descriptive Statistics and Correlations}


Scale reliabilities, descriptive statistics, correlation coefficients, and tests of significance for all outcome variables at pretest are reported in Table 1. Consistent with current research guidelines in applied research (Zhu, 2012), the magnitude of observed differences is also reported (Cohen's $d$ ). As can be observed, the participants' scores were not different prior to the intervention. Furthermore, scores for perceived task-involving climate, task orientation, and pleasant/functional PBS states were larger than scores of ego-involving climate, ego orientation, and unpleasant/dysfunctional PBS states (see Table 1), respectively. Task-involving climate was found to be: (a) positively correlated with task orientation and pleasant/functional PBS states, and (b) negatively correlated with unpleasant/dysfunctional PBS states. Furthermore, ego-involving climate was found to be: (a) positively correlated with ego orientation and unpleasant/dysfunctional PBS states, and (b) negatively correlated with pleasant/functional PBS states. Though statistically significant, the correlations were low to moderate (Zhu, 2012).

\section{Intervention Effects}

The results derived from the $2 \times 2$ (group $\times$ test) RM-ANCOVA are given in Table 2 . Perceived task-involving and ego-involving climates, as well as pleasant/functional and unpleasant/dysfunctional PBS states yielded statistically significant results on the $2 \times 2$ (group $\times$ test) interaction. Post-hoc tests showed medium to large differences in the expected direction between the two groups at post-test on both task-involving $(p<.001, d=.80)$ and ego-involving climates $(p<.001, d=.55)$, as well as on both pleasant/functional $(p=.035, d$ $=.45)$ and unpleasant/dysfunctional PBS states $(p<.001, d=.64)$. Statistically significant results can be attributed to the changes observed in the ego-involved group from pretest to post-test. In particular, compared to pretest scores the ego-involved group reported lower post-test scores in perceived task-involving climate and pleasant/functional PBS states, and higher scores in perceived ego-involving climate and unpleasant/dysfunctional PBS states. In 
summary, findings indicate that the intervention was effective in creating a particular psychological climate and in triggering consistent PBS states. Changes in the ego-involved group were more pronounced than in the task-involved group. Individual's goal orientation results were not statistically significant.

\section{Discrete PBS States}

Profile analyses were performed separately on the post-test scores of pleasant/functional and unpleasant/dysfunctional PBS states. The dependent variables were the seven pleasant/functional or seven unpleasant/dysfunctional PBS states, while the independent variable was the experimental group. Statistically significant differences by group were observed on pleasant/functional PBS states, $F(1,106)=5.39, p=.022, \eta^{2}=.05$, power $=.63$, and unpleasant/dysfunctional PBS states, $F(1,106)=11.02, p=.001, \eta^{2}=.09$, power $=.91$. Follow-up univariate analysis $(p<.05)$ showed that the ego-involved group reported lower scores on pleasant/functional emotion, cognition, motivation, and performance items, and higher scores on unpleasant/dysfunctional emotion, motivation, bodily reaction, performance, and communication items. The complete pattern of results is illustrated in Figure 1.

\section{Discussion}

\section{Effects of Task-involving and Ego-involving Climate Interventions}

In the present study, we examined the effects of task-involving and ego-involving climate manipulations on students' climate perception and PBS states in a PE setting. The intervention was grounded in the six dimensions of the TARGET model (Task approach, Authority role, Recognition dynamics, Grouping behavior, Evaluation standards, and Timing appropriateness) for enhancing task-involving climate (see Morgan \& Kingston, 2008). In the first experimental group, the model was applied, as usually recommended, to create a taskinvolving climate with emphasis placed on effort, personal improvement, and cooperation 
(see Braithwaite et al., 2011). In the second experimental group, the different dimensions of the model were manipulated to produce an ego-involving atmosphere, with a focus on outcome and interpersonal competition rather than on learning and self-referenced achievements. This procedure allowed us to investigate the impact of teachers' attitudes and behaviors on student's motivational perceptions and PBS states. Findings showed that a clearcut task- or ego-involving climate influenced students' climate perception, overriding the individual's dispositional goal orientation. In particular, the ego-involved group reported lower post-test scores in perceived task-involving climate and higher scores in ego-involving climate. In an interactionist approach, goal orientation is viewed as an individual variable that, in achievement contexts, will produce the probability of adopting a certain goal of action, while motivational climate is considered as a situational factor potentially altering this probability (Treasure, 2001). Robert and Treasure (1992) argued that motivational climates are influenced by teachers' preferences for fostering an either primarily task- or ego-oriented climate. The influence of an either task- or ego-involving teaching atmosphere on 14/15years-old students' psychobiosocial states was examined in this study. At the initial test, both groups of students presented almost equal scores (see Table 2), higher in perceived taskinvolving climate than ego-involving climate. This is consistent with the school context, where a task-involving climate is functional for the achievement of a number of educational goals that characterize PE programs. The lack of changes in the task-involved group from pretest to post-test is coherent with this view, in that the experimental situation was likely similar to the motivational climate of the regular course.

Regarding the emotional consequences of a specific motivational climate, our results are in line with previous findings in PE, where researchers have used the achievement goal theory as a framework to examine different motivational climate interventions (e.g., Barkoukis, Koidou, \& Tsorbatzoudis, 2010; Escartí \& Gutiérrez, 2001; Weigand \& Burton, 
2002). For instance, the studies considered in the Braithwaite et al.'s (2011) meta-analysis showed adaptive outcomes (such as enjoyment, commitment, and confidence) on students involved in a task-involving climate condition, whereas maladaptive outcomes (such as anxiety and boredom) resulted in an ego-involving climate condition. In our study, the participants of the ego-involved group reported lower scores in pleasant/functional PBS states and higher scores in unpleasant/dysfunctional PBS states after the intervention. Previous research results showed ego-involving climate associated with negative affective experiences (see Biddle, 2001; Treasure \& Roberts, 2001). Liukonnen, Barkoukis, Watt, and Jaakkola (2010) found that an ego-involving climate in PE was negatively related to enjoyment, suggesting that placing emphasis on social comparison undermines students' feelings of enjoyment. Furthermore, Liukonnen et al. showed ego-involving climate associated with higher levels of anxiety. A motivational climate, which emphasizes social comparison and performance outcomes rather than individual learning and improvement, can create feelings of worry and apprehension. The possibility of failing and demonstrating low competence to others may create an unacceptable and embarrassing situation, thereby resulting in negative emotional experiences.

Regarding discrete PBS states, at post-test the ego-involved group reported lower scores on pleasant/functional emotion, performance, and motivation than the task-involved group, and higher scores on the same unpleasant/dysfunctional PBS states. These states were represented by adjectives such as "happy, joyful" or "sad" for pleasant/unpleasant emotion, "proficient" or "unsure" for functional/dysfunctional performance, "involved, determined" or "unmotivated" for functional/dysfunctional motivation. These findings highlight the linkage among various aspects of the multidimensional emotion-related experience in PE, in which emotional and motivational contents are consistent with performance contents.

\section{Intervention Implications}


From an applied perspective, our findings underline the need for PE teachers to carefully consider the way they structure lessons, because adopting a task-involving climate can be critical in enhancing student motivation. Morgan and Kingston (2008) developed a mastery intervention program for teacher education, based on self-observation of filmed PE lessons. The program was specifically designed to educate the teachers to create a taskinvolving climate according to the TARGET model, and stimulate them to reflect upon their own teaching behaviors and change them if necessary. The effects of the program on teaching behaviors were also assessed; after the intervention teachers demonstrated a significant increase in mastery behaviors and were able to set more mastery goals, focus more on selfreferenced improvement, and use a greater variety of tasks. Future studies targeting the development of teachers' instructional and leadership styles are warranted, as PE teachers are seen as essential for promoting well-being and exercise habits.

PE can be an effective context in which to encourage young people to practice sport or do exercise both inside and outside school in order to promote their health and well-being, and stimulate future physical activity or sport habits (Wallhead \& Buckworth, 2004). A taskinvolving climate proved to be significant in fostering the individuals' intention to be physically active and to practice sport or exercise outside school (Escartí \& Gutiérrez, 2001). Moreover, a task-involving motivational climate has been recognized to be the source of positive feelings in PE (such as enjoyment, fun, and pleasant emotions), which can increase intentions to be active and participate in organized and unorganized physical activity (Garcia Bengoechea, Sabiston, Ahmed, \& Farnous, 2010). PE provides opportunity to involve almost all school-aged youngsters and, thus, is an important venue by which young people can be motivated to be physically active outside of school.

\section{Limitations and Issues for Future Research}


Limitations in our study should be acknowledged and accounted for in future research. First, the study design was quasi-experimental in nature because the purpose was to investigate motivational climate interventions in a real world setting. For practical reasons, it was impossible to randomly assign participants to task- and ego-involved groups for a two months intervention. It should also be noted that, although the two teachers were exposed to a similar training protocol, their idiosyncratic personalities and communication styles may explain part of the variance in the results. Moreover, the sample included female participants only. Previous research conducted in the PE setting (Bortoli \& Robazza, 2005; Papaioannou \& Kouli, 1999; Walling \& Duda, 1995) showed that boys were more ego-oriented than girls, and tended to perceive the motivational climate as more ego-involving (Papaioannou \& Kouli, 1999). Consequently, boys may experience different levels of pleasant and unpleasant PBS states than girls. Future studies should involve both female and male participants, to take into account possible gender differences in the experience of PBS states. The lack of a control group is another limitation. Future studies based on a true rather than quasi-experimental design, and adding mastery goal and performance goal avoidance groups (in agreement with the $2 \times 2$ model; Elliot $\&$ McGregor, 2001), may yield more robust findings. Finally, future studies may also consider hierarchical linear modeling to examine between-group differences as pertaining to various nested data levels, such as "students" (i.e., level 1) from a given “teacher" (i.e., level 2) working in a specific "school” (i.e., level 3).

\section{What Does This Article Add?}

The relationship between motivational atmosphere and PBS states has been previously investigated in PE (Bortoli et al., 2014; Bortoli \& Robazza, 2007) and youth sport (Bortoli et al., 2012) using a cross-sectional research design, in which firm conclusions about causal relations among the variables cannot be established. In contrast, the intervention design implemented in the current study provide stronger evidence of the effects of motivational 
climate toward students' PBS states. Furthermore, taking into account a range of PBS states, rather than focusing on global affective responses, would enable a better understanding of individual's emotional experiences.

Findings suggest that applying the TARGET model indications can modify high school students' perceptions of motivational climate and induce PBS states consistent with a given motivational atmosphere. PE teachers should be aware of the potentially negative effects of ego-involving situations. They should create a task-involving climate and pleasant emotional experiences for their students. Appropriate PE programs have the potential to elicit students' interest, enjoyment, and pleasant PBS states, as well as to increase motivation for physical activities, and thus have a protective effect against situations that place adolescents at risk of adopting sedentary behaviors. 


\section{References}

Ames, C. (1992). Achievement goals, motivational climate, and motivational processes. In G.

C. Roberts (Ed.), Motivation in sport and exercise (pp. 161-176). Champaign, IL: Human Kinetics.

Barkoukis, V., Koidou, E., \& Tsorbatzoudis, H. (2010). Effects of a motivational climate intervention on state anxiety, self-efficacy, and skill development in physical education. European Journal of Sport Science, 10, 167-177. doi:

$10.1080 / 17461390903426634$

Bassoli, L., Boncinelli, S., Brizzi, L., Curci, R., Signorelli, D., Pazardjiklian, I., \& Pellai, A. (2004). Survey of physical activity and doping in a sample of 6,915 students aged 1418 years. Minerva Pediatrica, 56, 317-326.

Biddle, S. J. H. (2001). Enhancing motivation in physical education. In G. C. Roberts (Ed.), Advances in motivation in sport and exercise (pp. 101-127). Champaign, IL: Human Kinetics.

Biddle, S. J. H., Whitehead, S. H., O’Donovan, T. M., \& Nevi, M. E. (2005). Correlates of participation in physical activity for adolescent girls: A systematic review of recent literature. Journal of Physical Activity and Health, 2, 423-434.

Bortoli, L., Bertollo, M., Filho, E., \& Robazza, C. (2014). Do psychobiosocial states mediate the relationship between perceived motivational climate and individual motivation in youngsters? Journal of Sports Sciences, 32, 572-582. doi:

$10.1080 / 02640414.2013 .843017$

Bortoli, L., Colella, D., Morano, M., Berchicci, M., Bertollo, M, \& Robazza, C. (2008). Teacher-initiated motivational climate in physical education questionnaire in an Italian sample. Perceptual and Motor Skills, 106, 207-214. doi: 10.2466/PMS.106.1.207-214 
Bortoli, L., Messina, G., Zorba, M., \& Robazza, C. (2012). Contextual and individual influences on antisocial behaviour and psychobiosocial states of youth soccer players. Psychology of Sport and Exercise, 13, 397-406. doi: 10.1016/j.psychsport.2012.01.001

Bortoli, L., \& Robazza, C. (2005). Italian version of the Task and Ego Orientation in Physical Education Questionnaire. Perceptual and Motor Skills, 101, 901-910. doi: 10.2466/pms.101.3.901-910

Bortoli, L., \& Robazza, C. (2007). Dispositional goal orientations, motivational climate, and psychobiosocial states in physical education. In L. A. Chiang (Ed.), Motivation of exercise and physical activity (pp. 119-133). New York, NY: Nova Science.

Braithwaite, R., Spray, C. M., \& Warburton, V. E. (2011). Motivational climate interventions in physical education: A meta-analysis. Psychology of Sport and Exercise, 12, 628638. doi: 10.1016/j.psychsport.2011.06.005

Duda, J. L., \& Nicholls, J. G. (1992). Dimensions of achievement motivation in schoolwork and sport. Journal of Educational Psychology, 84, 290-299. doi: 10.1037/00220663.84.3.290

Elliot, A. J., \& McGregor, H. A. (2001). A $2 \times 2$ achievement goal framework. Journal of Personality and Social Psychology, 80, 501-519. doi: 10.1037/0022-3514.80.3.501

Escartí, A., \& Gutiérrez, M. (2001). Influence of the motivational climate in physical education on the intention to practice physical activity or sport. European Journal of Sport Science, 1, 1-12.

Garcia Bengoechea, E. G., Sabiston, C. M., Ahmed, R., \& Farnoush, M. (2010). Exploring links to unorganized and organized physical activity during adolescence: The role of gender, socioeconomic status, weight status, and enjoyment of physical education. Research Quarterly for Exercise and Sport, 81, 7-16.

Hanin, Y. L. (Ed.). (2000). Emotions in sport. Champaign, IL: Human Kinetics. 
Hanin, Y. L. (2007). Emotions in sport: Current issues and perspectives. In G. Tenenbaum \& R. Eklund (Eds.), Handbook of sport psychology (3rd ed., pp. 31-58). Hoboken, NJ: Wiley.

Jaakkola, T., \& Liukkonen, J. (2006). Changes in students' self-determined motivation and goal orientation as a result of motivational climate intervention within high school physical education classes. International Journal of Sport and Exercise Psychology, 4, 302-324.

Liukkonen, J., Barkoukis, V., Watt, A., \& Jaakkola, T. (2010). Motivational climate and students' emotional experiences and effort in physical education. The Journal of Educational Research, 103, 295-308. doi:10.1080/00220670903383044

Morgan, K., \& Kingston, K. (2008). Development of a self-observation mastery intervention programme for teacher education. Physical Education and Sport Pedagogy, 13, 109129. doi: $10.1080 / 17408980701345634$

Mouratidis, A., Vansteenkiste, M., Lens, W., \& Vanden Auweele, Y. (2009). Beyond positive and negative affect: Achievement goals and discrete emotions in the elementary physical education classroom. Psychology of Sport and Exercise, 10, 336-343. doi: 10.1016/j.psychsport.2008.11.004

Papaioannou, A. (1998). Students' perceptions of the physical education class environment for boys and girls and the perceived motivational climate. Research Quarterly for Exercise and Sport, 69, 267-275.

Papaioannou, A., \& Goudas, M. (1999). Motivational climate of the physical education class. In Y. Vanden Auweele, F. Bakker, S. Biddle, M. Durand, \& R. Seiler (Eds.), Psychology for physical educators (pp. 51-68). Champaign, IL: Human Kinetics. 
Papaioannou, A., \& Kouli, O. (1999). The effect of task structure, perceived motivational climate and goal orientations on students' task involvement and anxiety. Journal of Applied Sport Psychology, 11, 51-71. doi: 10.1080/10413209908402950

Robazza, C., \& Bortoli, L. (2005). Changing students' attitudes towards risky motor tasks: An application of the IZOF model. Journal of Sports Sciences, 23, 1075-1088. doi: $10.1080 / 02640410500128205$

Roberts, G. C., \& Treasure, D. C. (1992). Children in sport. Sport Science Review, 1, 46-64. Roberts, G. C., Treasure, D. C., \& Conroy, D. E. (2007). Understanding the dynamics of motivation in sport and physical activity: An achievement goal interpretation. In G. Tenenbaum \& R. Eklund (Eds.), Handbook of sport psychology (3rd ed., pp. 3-30). Hoboken, NJ: Wiley.

Scanlan, T. K., \& Simons, J. P. (1992). The construct of sport enjoyment. In G. C. Roberts (Ed.), Motivation in sport and exercise (pp. 199-215). Champaign, IL: Human Kinetics.

Tabachnick, B. G., \& Fidell, L. S. (2013). Using multivariate statistics (6th ed.). New Jersey, NJ: Pearson Education.

Treasure, D. C. (2001). Enhancing young people's motivation in youth sport: An achievement goal approach. In G. C. Roberts (Ed.), Advances in motivation in sport and exercise (pp. 79-100). Champaign, IL: Human Kinetics.

Treasure, D. C., \& Roberts, G. C. (2001). Students' perceptions of the motivational climate, achievement beliefs, and satisfaction in physical education. Research Quarterly for Exercise and Sport, 72, 165-175.

Wallhead, T. L., \& Buckworth, J. (2004). The role of physical education in the promotion of youth physical activity. Quest, 56, 285-301. 
Walling, M. D., \& Duda, J. L. (1995). Goals and their associations with beliefs about success in and perceptions of the purposes of physical education. Journal of Teaching in Physical Education, 14, 140-156.

Weigand, D. A., \& Burton, S. (2002). Manipulating achievement motivation in physical education by manipulating the motivational climate. European Journal of Sport Science, 2, 1-14.

Zhu, W. (2012). Sadly, the earth is still round $(p<0.05)$. Journal of Sport and Health Science, 1, 9-11. doi: 10.1016/j.jshs.2012.02.002 
Table 1

Descriptive statistics, correlations coefficients, alpha coefficients, and t-tests at pretest on the scores of the experimental groups

\begin{tabular}{|c|c|c|c|c|c|c|c|c|c|c|}
\hline Measure & $M$ & $S D$ & 1 & 2 & 3 & 4 & 5 & 6 & $t$-test & $p$ \\
\hline 3. Task orientation & 4.09 & 0.52 & $.54^{\mathrm{ft}}$ & -.18 & $(.84)$ & & & & 0.31 & .76 \\
\hline 5. Pleasant/functional PBS states & 2.18 & 0.64 & $.35^{\dagger}$ & $-.37^{\dagger}$ & $.32^{\dagger}$ & -.13 & $(.83)$ & & 0.23 & .82 \\
\hline 6. Unpleasant/dysfunctional PBS states & 0.54 & 0.42 & $-.33^{\dagger}$ & $.38^{\dagger}$ & $-.31^{\dagger}$ & .05 & $-.42^{f f}$ & $(.75)$ & 0.29 & .78 \\
\hline
\end{tabular}

Note. Mean $(M)$ and Standard Deviation $(S D)$. Alpha coefficients are in brackets on the diagonal. ${ }^{\dagger}$ Low correlation, ${ }^{\text {ft }}$ Moderate correlation. 
Table 2

Interaction results of $2 \times 2($ group $\times$ test $)$ repeated-measures analysis of covariance

\begin{tabular}{|c|c|c|c|c|c|c|c|c|c|c|}
\hline \multirow[b]{3}{*}{ Dependent variable } & \multicolumn{3}{|c|}{ Task-involved group } & \multicolumn{3}{|c|}{ Ego-involved group } & \multirow[b]{3}{*}{$F(1,104)$} & \multirow[b]{3}{*}{$p$} & \multirow[b]{3}{*}{$\eta_{\mathrm{p}}^{2}$} & \multirow[b]{3}{*}{ Power } \\
\hline & Pretest & Post-test & & Pretest & Post-test & & & & & \\
\hline & $M(S D)$ & $M(S D)$ & $d$ & $M(S D)$ & $M(S D)$ & $d$ & & & & \\
\hline Task-involving climate & $4.02(0.56)$ & $4.07(0.42)$ & .10 & $4.03(0.38)$ & $3.64(0.63)$ & -.75 & $14.13 * *$ & .000 & .12 & .96 \\
\hline Ego-involving climate & $2.04(0.66)$ & $1.94(0.77)$ & -.14 & $2.05(0.47)$ & $2.38(0.83)$ & .49 & $6.90 *$ & .010 & .06 & .74 \\
\hline Pleasant/functional PBS states & $2.19(0.84)$ & $2.29(0.66)$ & .13 & $2.17(0.38)$ & $2.01(0.58)$ & -.33 & $5.39 *$ & .022 & .05 & .63 \\
\hline Unpleasant/dysfunctional PBS states & $0.55(0.44)$ & $0.49(0.40)$ & -.14 & $0.53(0.40)$ & $0.83(0.63)$ & .57 & $13.59 * *$ & .000 & .12 & .96 \\
\hline Task orientation & $4.11(0.54)$ & $4.13(0.56)$ & .04 & $4.08(0.51)$ & $3.96(0.48)$ & -.24 & & & & \\
\hline Ego orientation & $2.83(0.87)$ & $2.45(0.88)$ & -.43 & $2.67(0.81)$ & $2.51(0.85)$ & -.19 & & & & \\
\hline
\end{tabular}

Note. Mean $(M)$ and Standard Deviation $(S D) . * p<.05, * * p<.01$. Task orientation and Ego orientation were entered as covariates in the analysis. 